\title{
Utilization and Costs of Compounded Medications for Commercially Insured Patients, 2012-2013
}

\author{
Timothy McPherson, PhD; Patrick Fontane, PhD; Reethi lyengar, PhD; and Rochelle Henderson, PhD
}

\begin{abstract}
BACKGROUND: Although compounding has a long-standing tradition in clinical practice, insurers and pharmacy benefit managers have instituted policies to decrease claims for compounded medications, citing questions about their safety, efficacy, high costs, and lack of FDA approval. There are no reliable published data on the extent of compounding by community pharmacists nor on the fraction of patients who use compounded medications. Prior research suggests that compounded medications represent a relatively small proportion of prescription medications, but those surveys were limited by small sample sizes, subjective data collection methods, and low response rates.
\end{abstract}

OBJECTIVE: To determine the number of claims for compounded medications on a per user per year (PUPY) basis and the average ingredient cost of these claims among commercially insured patients in the United States for 2012 and 2013.

METHODS: This study used prescription claims data from a nationally representative sample of commercially insured members whose pharmacy benefits were managed by a large pharmacy benefit management company. A retrospective claims analysis was conducted from January 1, 2012, through December 31, 2013. Annualized prevalence, cost, and utilization estimates were drawn from the data. All prescription claims were adjusted to 30 -day equivalents. Data-mining techniques (association rule mining) were employed in order to identify the most commonly combined ingredients in compounded medications.

RESULTS: The prevalence of compound users was $1.1 \%(245,285)$ of eligible members in 2012 and $1.4 \%(323,501)$ in 2013, an increase of $27.3 \%$. Approximately $66 \%$ of compound users were female, and the average age of a compound user was approximately 42 years throughout the study period. The geographic distribution of compound user prevalence was consistent across the United States. Compound users' prescription claims increased $36.6 \%$ from 2012 to 2013 , from approximately 7.1 million to approximately 9.7 million prescriptions. The number of claims for compounded medications increased by $34.2 \%$ during the same period, from 486,886 to 653,360 . PUPY utilization remained unchanged at 2 prescriptions from 2012 to 2013. The most commonly compounded drugs were similar for all adult age groups and represented therapies typically indicated for chronic pain or hormone replacement therapy. The average ingredient cost for compounded medications increased by $130.3 \%$ from 2012 to 2013 , from $\$ 308.49$ to $\$ 710.36$. The average ingredient cost for these users' noncompounded prescriptions increased only $7.7 \%$, from $\$ 148.75$ to $\$ 160.20$. For comparison, the average ingredient cost for all prescription users' claims was $\$ 81.50$ in 2012 and increased by 3.8\% to $\$ 84.57$ in 2013.

CONCLUSIONS: Compound users represented $1.4 \%$ of eligible members in 2013. The average ingredient cost for compound users' compounded prescriptions (\$710.36) was greater than for noncompounded prescriptions (\$160.20). The 1-year increase in average compounded prescription costs $(\mathbf{1 3 0 . 3 \% )}$ was also greater than for noncompounded prescriptions $(\mathbf{7 . 7 \%})$.
Although prevalence of compound users and the PUPY utilization for compounded prescriptions increased only slightly between 2012 and 2013, the mean and median cost of compounded medications increased dramatically during this time. Text mining revealed that drug combinations characteristic of topical pain formulations were among the most frequently compounded medications for adults.

\section{J Manag Care Spec Pharm. 2016;22(2):172-81}

Copyright $\odot 2016$, Academy of Managed Care Pharmacy. All rights reserved.

\section{What is already known about this subject}

Scrutiny of compounded medications by insurers and regulatory agencies has recently increased. There are no published objective data on the number of compounded medications dispensed by community pharmacists nor on the costs associated with these prescriptions.

Prior studies on the extent of compounding were based on surveys with small numbers of responses and respondents' selfreported data.

\section{What this study adds}

This is the first published study to profile trends in use and cost of compounded medications using an objective, nationally representative dataset.

This study applies association data-mining procedures to discern the most often compounded drugs and the conditional likelihood to observe the occurrence of particular drug combinations.

\footnotetext{
ommunity pharmacists have traditionally compounded medications to provide patients with alternative doses or combinations of drugs, allergen-free formulations, or dosage forms that are not commercially available. ${ }^{1}$ Pharmacy compounding allows for "the preparation, mixing, assembling, altering, packaging, and labeling of a drug, drug-delivery device, or device in accordance with a licensed practitioner's prescription, medication order, or initiative based on the practitioner/patient/pharmacist/compounder relationship in the course of professional practice."

Although compounding has a long-standing tradition in clinical practice, insurers and pharmacy benefit managers have recently instituted policies to decrease claims for compounded
} 
medications, citing questions about their safety, efficacy, high costs, and lack of U.S. Food and Drug Administration (FDA) approval. ${ }^{3-5} \mathrm{~A}$ heightened focus has been placed on the practice of compounding by citizens, regulators, and insurers since the 2013 tragedy of contaminated steroid injections from the New England Compounding Center, which caused serious infections and other injuries to at least 751 patients and resulted in at least 64 patient deaths. ${ }^{6-8}$ The use of compounded oral, topical, and transdermal medications dispensed by community pharmacies is also increasingly being scrutinized. ${ }^{9}$ Proponents of compounding have argued that compounded medications represent invaluable personalized therapies for patients who are not treated adequately with traditional FDA-approved drug products. ${ }^{10,11}$

Amid this debate, 2 important questions remain unanswered: How many patients use compounded medications per year, and how much do the medications cost? Survey research suggests that compounded medications represent a relatively small portion of prescription medications, ranging from $2.3 \%$ to $12.2 \% \cdot{ }^{12-15}$ However, those studies were limited by small sample sizes, subjective data collection methods, and low response rates. As such, there are no reliable published data on the extent of compounding by community pharmacists nor on the fraction of patients who use compounded medications.

Considering that $61.8 \%$ of the U.S. population has private health insurance coverage and the Affordable Care Act requires prescription drug coverage as 1 of the 10 essential benefits that health plans must provide, prescription claims data can be leveraged to examine prevalence, cost, and use trends among compounded medications. ${ }^{16,17}$ With limited information about the usage patterns of compounded medications, prescription claim databases offer the advantages of objective data, sample sizes that are representative of a large proportion of the U.S. population, and detailed information on compounded medications.

The objective of this study was to determine the number of claims for compounded medications on a per user per year (PUPY) basis and the average ingredient cost of these claims among commercially insured patients in the United States for 2012 and 2013. An additional goal was to examine which drugs were most often compounded together.

\section{Methods}

\section{Population}

This study used prescription claims data from a nationally representative sample of commercially insured members whose pharmacy benefits were managed by a large pharmacy benefit management company. The health plan sponsors for these benefits included private- and public-sector employer groups, managed care organizations, third-party administrators, and unions. Inclusion was limited to members who were eligible for pharmacy benefits at any time between January 1, 2012, and December 31, 2013.

\section{Study Design}

A retrospective claims analysis was conducted from January 1 , 2012, through December 31, 2013. Annualized prevalence, cost, and use estimates were drawn from the data. All prescription claims were adjusted to 30-day equivalents by dividing the days supply by 30.4. This normalization is based on an average month, calculated as 365 days per year $\div 12$ months per year $=30.4$ days per month .

Under provisions of the Health Insurance Portability and Accountability Act of 1996, all data specific to individual patients were removed from internal analytical datasets to maintain the privacy of protected health information. The study was declared exempt by both Southern Illinois University Edwardsville and St. Louis College of Pharmacy institutional review boards, as only de-identified administrative pharmacy claims data were used.

\section{Study Variables}

The primary outcome measures were number and percentage of compound users by age bands, prevalence of users, PUPY utilization, and cost associated with compounded medication. Members were defined as persons eligible for prescription benefits at any time between January 1, 2012, and December 31, 2013. Prescription medication users were defined as members who had at least 1 claim for a prescription medication between January 1, 2012, and December 31, 2013. Compound users were defined as those prescription medication users who had at least 1 claim for a compounded medication during the same period. Compounded medications were identified at the point of service by the medication provider and submitted to the pharmacy benefit manager. Age categories were birth-9 years, 10-19 years, 20-29 years, 30-39 years, 40-49 years, 50-59 years, 60-69 years, and 70 years or older. The prevalence of compound users was calculated as the number of patients with at least 1 compound prescription in a calendar year divided by the number of members eligible for pharmacy benefits for that year, expressed as a percentage. Utilization measures were based on prescription claim counts. PUPY utilization for compounded medications was calculated as the number of 30-day adjusted compounded prescriptions divided by the number of compound medication users per year. Average cost per prescription was calculated by dividing the total ingredient cost of compounded medication claims by the number of 30-day adjusted compounded medication prescriptions per year. Ingredient cost was calculated according to the average wholesale price, without administrative or dispensing fees.

\section{Analysis}

Descriptive and bivariate statistics were generated for the prevalence of use, cost, and utilization measures for 2012 and 2013. Prevalence of compound users was analyzed by age groups and sex as well as by geography. Most often-used drugs were also 


\begin{tabular}{|c|c|c|c|}
\hline & 2012 & 2013 & Change \\
\hline Eligible members & $22,314,101$ & $22,745,508$ & $\begin{array}{r}431,407 \\
(1.9 \%) \\
\end{array}$ \\
\hline Prescription medication users & $14,960,649$ & $15,110,518$ & $\begin{array}{r}149,869 \\
(1.0 \%)\end{array}$ \\
\hline $\begin{array}{l}\text { Prevalence of prescription } \\
\text { medication users (\%) }\end{array}$ & 67.0 & 66.4 & -0.9 \\
\hline Average age, years (SD) & $\begin{array}{r}36.9 \\
(20.7) \\
\end{array}$ & $\begin{array}{r}36.8 \\
(20.6) \\
\end{array}$ & $-0.1 \mathrm{yr}$ \\
\hline Female & $11,508,347$ & $11,713,474$ & $1.8 \%$ \\
\hline Percent female & 51.6 & 51.5 & -0.2 \\
\hline Compound users & 245,285 & 323,501 & $\begin{array}{r}78,216 \\
(31.9 \%) \\
\end{array}$ \\
\hline Prevalence of compound users (\%) & 1.1 & 1.4 & 27.3 \\
\hline Average age, years (SD) & $\begin{array}{r}41.8 \\
(21.3) \\
\end{array}$ & $\begin{array}{r}42.3 \\
(21.1) \\
\end{array}$ & $0.5 \mathrm{yr}$ \\
\hline Female & 162,471 & 212,590 & $30.8 \%$ \\
\hline Percent female & 66.2 & 65.7 & -0.8 \\
\hline
\end{tabular}

analyzed by age group to detect similarities/differences in the type of compounded drugs used by patients in different age bands and sexes.

In order to identify the most commonly combined ingredients in compounded medications, the data-mining technique of association rule was employed. Data mining is increasingly being used in health care research to examine myriad issues, including hospital infection control, screening of adverse drug reactions, prediction of heart disease, exposure to air pollution and respiratory illness, and diagnosis of medical conditions, and in clinical observations. ${ }^{18-23}$ However, to our knowledge, this is the first study to apply association rule mining to analyze compounded medications.

A priori algorithms for association rule mining were used in this study to identify drugs that were most often compounded together. An a priori algorithm uses an iterative approach where $\mathrm{n}$ item sets are used to explore $\mathrm{n}+1$ item sets. In this study, item sets refer to unique drugs or different combinations of drugs. This approach efficiently ascertains frequent sets in data.

To address the possibility of many frequently occurring combinations of drugs, minimum levels of support (frequency) and confidence (conditional probability) were used. Support refers to how many times a particular item/item set appears in the data, and confidence refers to the conditional probability of item y appearing when item/item set $\mathrm{x}$ is observed. In this study, we used a minimum support of $10 \%$ to determine how often a particular drug or a combination of drugs appeared in compound medication claims. In addition, a minimum confidence threshold of $50 \%$ was used to determine the drug combinations that occurred when a particular drug (with at least $10 \%$ support) was observed in compound medication claims.
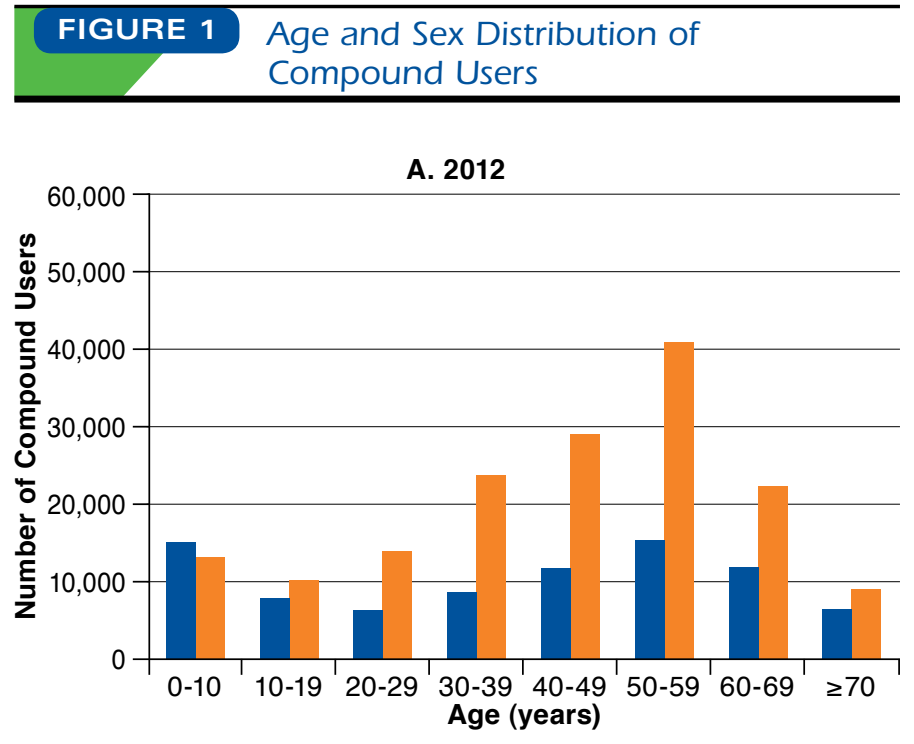

Male $(n=82,801) \quad$ Female $(n=162,471)$

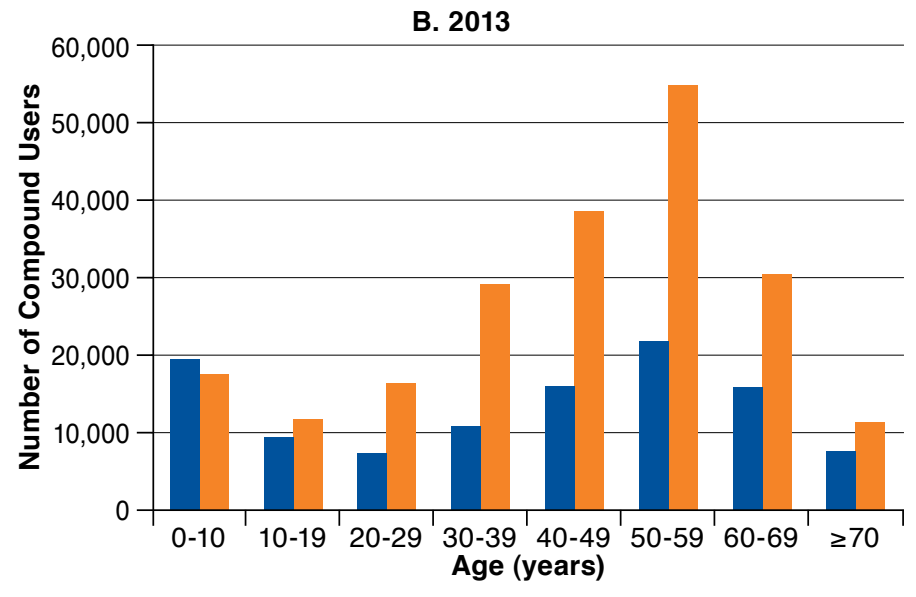

Male $(n=110,889) \quad$ Female $(n=212,590)$

\section{Results}

Claims from retail pharmacies constituted more than 99\% of total claims for compounded medications. The remaining claims originated from hospitals, mail-order pharmacies, or other nonretail pharmacies.

\section{Compound Users}

The demographics of the study population are summarized in Table 1. The number of eligible members in 2012 and 2013 were 22,314,101 and 22,745,508, respectively. Approximately two thirds of members used at least 1 prescription medication in both 2012 and 2013. The average age of prescription user was 36.9 years in 2012 and 36.8 years in 2013. Females 
A. Prevalence of Compound Users by State of Residence, 2013

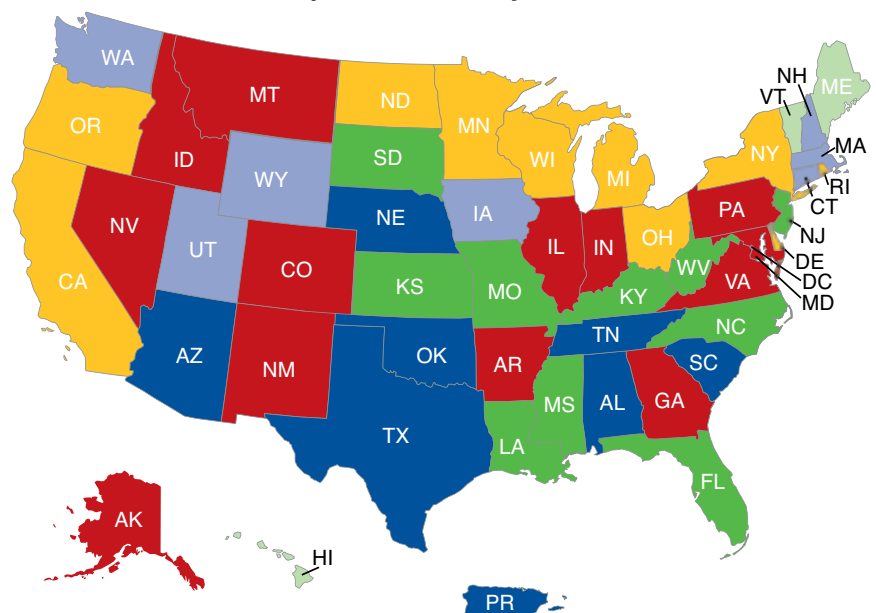

\begin{tabular}{|lcc|}
\hline \multicolumn{3}{|c|}{ Prevalence 2013 } \\
$\leq 0.6 \%$ & $0.7 \%-0.9 \%$ & $1.0 \%-1.1 \%$ \\
$1.2 \%-1.4 \%$ & $1.5 \%-1.7 \%$ & $\square 1.8 \%$ \\
\hline
\end{tabular}

B. Percentage Increase in Compound User Prevalence, 2012-2013

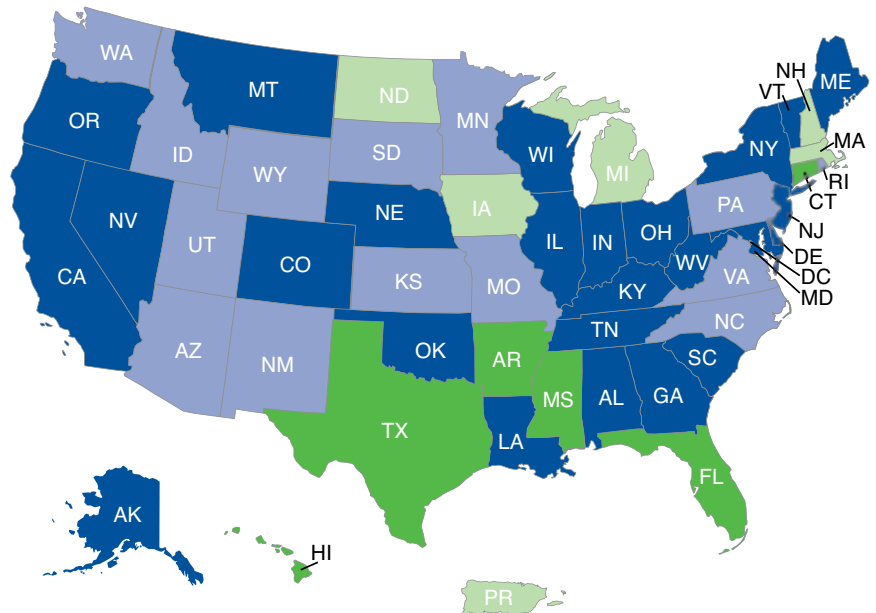

Prevalence Change Trend 2012-2013

Null or drop $\quad 0.1 \%-17.0 \%$

$17.1 \%-37.5 \% \square \geq 37.6 \%$ represented 51.6\% of prescription medication users in 2012 and $51.5 \%$ in 2013.

Compound users represented $1.1 \%$ of members $(245,285)$ in 2012 and $1.4 \%$ of members $(323,501)$ in 2013. Compound users increased by 78,216 from 2012 to 2013, while members increased by 431,407 . The prevalence of compound users thus increased by $27.3 \%$, while the number of members increased by $1.9 \%$. The prevalence of prescription medication users increased by only $1 \%$ during this time.

The distribution of compound users by age and sex is shown in Figure 1. The distributions were similar for 2012 (Figure 1A) and 2013 (Figure 1B). Overall, the average age of a compound user was approximately 42 years, and approximately two thirds of compound users were female. Patients younger than 10 years represented the only category with a greater number of male than female compound users. The greatest proportion of female compound users were aged 50-59 years (approximately 26\%), followed by 40-49 years (approximately 18\%), and 30-39 years and 60-69 years (approximately 14\% each). The age distribution for male compound users was bimodal, with the greatest proportion aged 50-59 years (approximately 19\%) and children younger than 10 years (approximately 18\%). The smallest proportion of compound users were aged 10-19 years and older than 70 years (approximately 6\% each) for females and 20-29 years and older than 70 years (approximately $7 \%$ each) for males.

The prevalence of compound users by state of residence for 2013 is shown in Figure 2A. The national average for preva- lence of compound users was $1.4 \%$, and 40 states exhibited compound user rates of $1 \%-2 \%$. Oklahoma (3.5\%), Tennessee (2.4\%), Alabama (2.3\%), and Texas (2.2\%) were the only states with prevalence greater than $2 \%$. The percentage increase in compound user prevalence from 2012 to 2013 is shown in Figure 2B. North Dakota was the only state with a decrease in the rate of compound users (-8.3\%), while Iowa, Massachusetts, Michigan, and New Hampshire exhibited no change. The largest increase in compound users occurred in Texas (69.2\%), Arkansas (62.5\%), Mississippi (54.5\%), Connecticut (50\%), Hawaii (50\%), New Jersey (50\%), and Florida (45.5\%). All other states exhibited an increase in prevalence of $7 \%$ to $37.5 \%$.

\section{Claims for Compounded Medications}

Compound users' prescription cost and utilization data are summarized in Table 2. There were nearly 7.1 million prescription claims for compound users in 2012, of which 486,886 (6.9\%) were compounded. In 2013, claims increased to nearly 9.7 million total prescriptions (a 36.6\% increase) and 653,360 compounded medications (a 34.2\% increase). The average utilization was 2 compounded prescriptions PUPY in both 2012 and 2013.

\section{Prescription Ingredient Costs}

Ingredient cost statistics for compound users' prescription claims are shown in Table 2 and Figure 3. Both the mean and median costs were greater for compounded medications than for noncompounded drugs. The average cost in 2012 was 


\begin{tabular}{|c|c|c|c|}
\hline $\begin{array}{l}\text { Medicatio } \\
\text { Compoun }\end{array}$ & \multicolumn{3}{|c|}{$\begin{array}{l}\text { Medication Costs and Utilizat } \\
\text { Compound Users, 2012-2013 }\end{array}$} \\
\hline & 2012 & 2013 & Change \\
\hline All prescriptions & $7,083,961$ & $9,677,954$ & $36.6 \%$ \\
\hline \multicolumn{4}{|l|}{ Ingredient cost } \\
\hline Mean (\$) & 163.42 & 209.76 & $28.4 \%$ \\
\hline Median (\$) & 32.57 & 27.86 & $-14.5 \%$ \\
\hline SD & $1,340.64$ & $38,715.93$ & \\
\hline Compounded prescriptions & 486,886 & 653,360 & $34.2 \%$ \\
\hline \multicolumn{4}{|l|}{ Ingredient cost } \\
\hline Mean $(\$)$ & 308.49 & 710.36 & $130.3 \%$ \\
\hline Median (\$) & 61.00 & 94.49 & $54.9 \%$ \\
\hline SD & $1,220.27$ & $3,076.07$ & \\
\hline PUPY utilization & 1.98 & 2.02 & $2.0 \%$ \\
\hline $\begin{array}{l}\text { Compounded prescriptions as } \\
\text { percentage of prescription claims }\end{array}$ & 6.9 & 6.8 & -1.8 \\
\hline $\begin{array}{l}\text { Compounded prescriptions as } \\
\text { percentage of ingredient cost }\end{array}$ & 13.0 & 22.9 & 76.2 \\
\hline Noncompounded prescriptions & $6,597,075$ & $9,024,593$ & $36.8 \%$ \\
\hline \multicolumn{4}{|l|}{ Ingredient cost } \\
\hline Mean $(\$)$ & 148.75 & 160.20 & $7.7 \%$ \\
\hline Median (\$) & 29.63 & 24.39 & $-17.7 \%$ \\
\hline SD & $1,351.35$ & $40,575.40$ & \\
\hline
\end{tabular}

PUPY= per user per year; $S D=$ standard deviation.

$\$ 308.49$ for compounded prescriptions and $\$ 148.75$ for noncompounded prescriptions. In 2013, the average cost of compounded prescriptions increased by $130.3 \%$ to $\$ 710.36$, while noncompounded prescriptions increased by $7.7 \%$ to $\$ 160.20$. For comparison, the average ingredient cost for all prescription users' claims was $\$ 81.50$ in 2012 and increased by 3.8\% to $\$ 84.57$ in 2013 . The median costs for both types of prescriptions were much lower than the average values, reflecting the influence of a small number of very high-cost claims on the cost distribution (Figure 3). The median cost for compounded medications increased $54.9 \%$, from $\$ 61.00$ to $\$ 94.49$, while noncompounded prescriptions decreased $17.7 \%$, from $\$ 29.63$ to $\$ 24.39$.

\section{Ingredients in Compounded Medications}

The 10 drugs most frequently included in compounded prescriptions in 2013 are shown in Table 3. Inactive ingredients (diluents, ointment bases, flavorings, etc.) were not included in this analysis, but they were included in the cost analysis (reported next). The lists for all adult age groups ( $\geq 20$ years) were similar for both 2012 (data not shown) and 2013. These drugs primarily represent therapies for pain management (gabapentin, baclofen, cyclobenzaprine, diclofenac, ketamine, lidocaine, bupivacaine, flurbiprofen) or hormone replacement (progesterone, estradiol, estriol, testosterone).

A text-mining procedure was applied to 2013 data to reveal drug combinations that were frequently compounded together. Claims for compounded medications containing gabapentin (the most frequently compounded drug overall) tended to also
FIGURE 3 Ingredient Cost Distribution for Compound Users' Prescription Claims

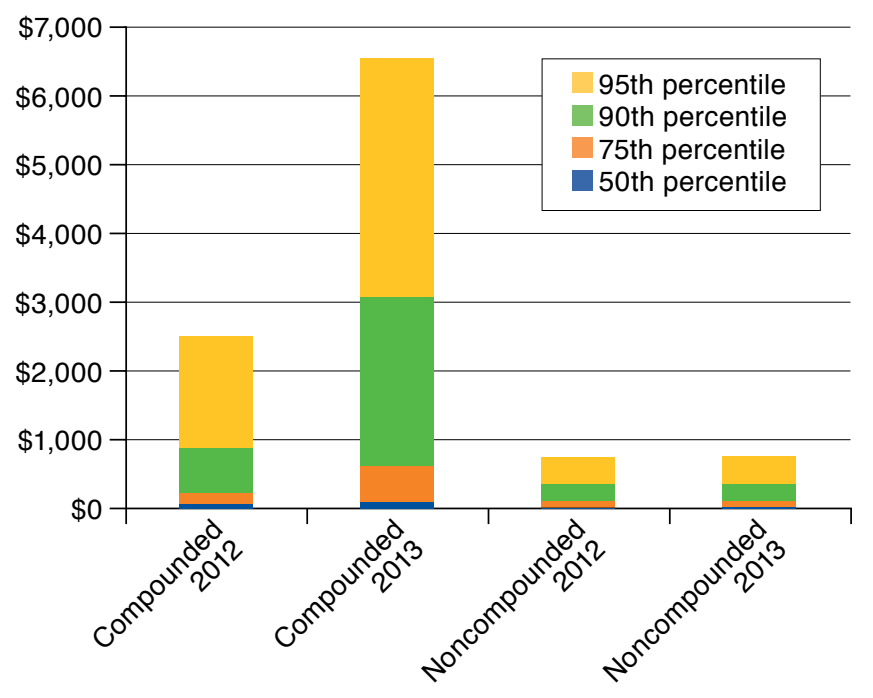

contain baclofen (67.7\%), cyclobenzaprine (64.1\%), and ketamine (52.2\%). Cyclobenzaprine (72.9\%), gabapentin (61.4\%), and baclofen (60.6\%) were frequently presented in claims with flurbiprofen. Neither progesterone nor fluticasone was associated with other drugs in the same claim at or above the 50\% confidence level.

The most frequently compounded drugs for children and adolescents $(<20$ years of age) were more diverse than those for adults (Table 3). The most commonly compounded medications for children were typically used for gastric acid suppression (omeprazole and lansoprazole); hypertension (enalapril, atenolol, spironolactone); and skin conditions (nystatin, hydrocortisone, zinc oxide, triamcinolone). The lists for 2012 (data not shown) and 2013 were substantially similar to each other.

The ingredients that contributed the greatest cumulative costs to compounded medication claims in 2013 are shown in Table 4. Both active and inactive ingredients were included in this analysis, as the cost for compounded medications includes all ingredients. Gabapentin, ketamine, cyclobenzaprine, baclofen, lidocaine, flurbiprofen, and fluticasone were consistently among the most expensive ingredients for patients older than 10 years in 2013. These drugs are commonly used individually and in various topical combinations for pain. ${ }^{24-27}$ Custom Lipo-Max cream (Professional Compounding Centers of America [PCCA], Houston, TX); Lipoderm (PCCA); and Pracasil Plus (PCCA) are proprietary nonmedicated bases for topical drug products. Custom Lipo-Max appeared in the lists for all groups aged at least 10 years, and Lipoderm appeared in the lists for all groups aged at least 20 years. There were several differences between the lists of most expensive ingredients for 
Utilization and Costs of Compounded Medications for Commercially Insured Patients, 2012-2013

TABLE 3 Ten Most Frequently Compounded Drugs by User Age and Sex, 2013

\begin{tabular}{|c|c|c|c|c|c|c|c|c|}
\hline \multirow{2}{*}{ 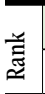 } & \multicolumn{2}{|c|}{$<10$ Years } & \multicolumn{2}{|c|}{ 10-19 Years } & \multicolumn{2}{|c|}{ 20-29 Years } & \multicolumn{2}{|c|}{ 30-39 Years } \\
\hline & $\mathrm{F}$ & M & $\mathrm{F}$ & M & $\mathrm{F}$ & M & $\mathrm{F}$ & $\mathrm{M}$ \\
\hline 1 & Omeprazole & Omeprazole & Baclofen & Baclofen & Baclofen & Baclofen & Gabapentin & Gabapentin \\
\hline 2 & Lansoprazole & Lansoprazole & Cyclobenzaprine $\mathrm{HCl}$ & Cyclobenzaprine $\mathrm{HCl}$ & Gabapentin & Cyclobenzaprine $\mathrm{HCl}$ & Progesterone & Baclofen \\
\hline 3 & Enalapril maleate & Enalapril maleate & Gabapentin & Lidocaine $\mathrm{HCl}$ viscous & Cyclobenzaprine $\mathrm{HCl}$ & Gabapentin & Baclofen & Cyclobenzaprine $\mathrm{HCl}$ \\
\hline 4 & Nystatin & Oseltamivir & Lidocaine $\mathrm{HCl}$ viscous & Methylcobalamin & Ketamine $\mathrm{HCl}$ & Ketamine $\mathrm{HCl}$ & Cyclobenzaprine $\mathrm{HCl}$ & Ketamine $\mathrm{HCl}$ \\
\hline 5 & Oseltamivir & Hydrocortisone & Diclofenac sodium & Salicylic acid & Diclofenac sodium & Diclofenac sodium & Ketamine $\mathrm{HCl}$ & Diclofenac sodium \\
\hline 6 & Hydrocortisone & Nystatin & Salicylic acid & Gabapentin & Progesterone & Lidocaine & Diclofenac sodium & Lidocaine \\
\hline 7 & Zinc oxide & Zinc oxide & Lidocaine & Diclofenac sodium & Lidocaine & Lidocaine $\mathrm{HCl}$ viscous & Lidocaine & Bupivacaine $\mathrm{HCl}$ \\
\hline 8 & Ursodiol & Baclofen & Hydrocortisone & Omeprazole & Bupivacaine $\mathrm{HCl}$ & Flurbiprofen & Bupivacaine $\mathrm{HCl}$ & Flurbiprofen \\
\hline 9 & Atenolol & Spironolactone & Ketamine $\mathrm{HCl}$ & Lidocaine & Flurbiprofen & Bupivacaine $\mathrm{HCl}$ & Flurbiprofen & Lidocaine $\mathrm{HCl}$ \\
\hline 10 & Baclofen & Triamcinolone acetonide & Bupivacaine $\mathrm{HCl}$ & Ketamine $\mathrm{HCl}$ & Lidocaine $\mathrm{HCl}$ & Lidocaine $\mathrm{HCl}$ & Testosterone & Testosterone \\
\hline \multirow{2}{*}{ 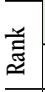 } & \multicolumn{2}{|c|}{$40-49$ Years } & \multicolumn{2}{|c|}{ 50-59 Years } & \multicolumn{2}{|c|}{$60-69$ Years } & \multicolumn{2}{|c|}{$\geq 70$ Years } \\
\hline & F & M & F & M & $\mathrm{F}$ & M & $\mathrm{F}$ & M \\
\hline 1 & Progesterone & Baclofen & Progesterone & Gabapentin & Progesterone & Gabapentin & Gabapentin & Gabapentin \\
\hline 2 & Gabapentin & Gabapentin & Estradiol & Baclofen & Estradiol & Baclofen & Baclofen & Baclofen \\
\hline 3 & Baclofen & Cyclobenzaprine $\mathrm{HCl}$ & Testosterone & Cyclobenzaprine $\mathrm{HCl}$ & Gabapentin & Cyclobenzaprine $\mathrm{HCl}$ & Cyclobenzaprine $\mathrm{HCl}$ & Cyclobenzaprine $\mathrm{HCl}$ \\
\hline 4 & Cyclobenzaprine $\mathrm{HCl}$ & Ketamine $\mathrm{HCl}$ & Gabapentin & Testosterone & Baclofen & Testosterone & Diclofenac sodium & Diclofenac sodium \\
\hline 5 & Testosterone & Diclofenac sodium & Baclofen & Ketamine $\mathrm{HCl}$ & Testosterone & Ketamine $\mathrm{HCl}$ & Ketamine $\mathrm{HCl}$ & Ketamine $\mathrm{HCl}$ \\
\hline 6 & Estradiol & Testosterone & Cyclobenzaprine $\mathrm{HCl}$ & Diclofenac sodium & Cyclobenzaprine $\mathrm{HCl}$ & Diclofenac sodium & Lidocaine & Testosterone \\
\hline 7 & Ketamine $\mathrm{HCl}$ & Lidocaine & Estriol & Lidocaine & Diclofenac sodium & Lidocaine & Bupivacaine $\mathrm{HCl}$ & Lidocaine \\
\hline 8 & Diclofenac sodium & Bupivacaine $\mathrm{HCl}$ & Diclofenac sodium & Bupivacaine $\mathrm{HCl}$ & Ketamine $\mathrm{HCl}$ & Bupivacaine $\mathrm{HCl}$ & Progesterone & Bupivacaine $\mathrm{HCl}$ \\
\hline 9 & Lidocaine & Flurbiprofen & Ketamine $\mathrm{HCl}$ & Flurbiprofen & Estriol & Flurbiprofen & Lidocaine $\mathrm{HCl}$ & Lidocaine $\mathrm{HCl}$ \\
\hline 10 & Bupivacaine $\mathrm{HCl}$ & Lidocaine $\mathrm{HCl}$ & Lidocaine & Lidocaine $\mathrm{HCl}$ & Lidocaine & Lidocaine $\mathrm{HCl}$ & Estradiol & Triamcinolone acetonide \\
\hline
\end{tabular}

2012 (data not shown) and 2013 for patients older than 10 years. Gabapentin, ketoprofen, ketamine, cyclobenzaprine, and baclofen appeared on some of the lists for 2012, but with lower frequency than in 2013. Similarly, the nonmedicated topical bases appeared less frequently in 2012 than in 2013.

The highest expense ingredients for patients younger than 10 years in both 2012 (data not shown) and 2013 primarily represented active drugs for treatment of a diverse array of medical conditions (influenza, gastric acid suppression, skin conditions). The inactive ingredients were Pracasil Plus (2013), sodium bicarbonate (2013), and PCCA-Plus oral syrup vehicle (2012 and 2013).

\section{Discussion}

The current study has established that compound users represented a small but increasing proportion of eligible members for the study period of 2012-2013. The rate of increase in prevalence of compound users (27.3\%) and the number of claims for compounded medications (34.2\%) were several times greater than the rate of increase in eligible members (1.9\%). Utilization was consistent at approximately 2 compounded prescriptions PUPY. There was a concurrent increase of $130.3 \%$ in the mean ingredient cost for compounded medications. The total ingredient costs for compounded medications increased from $\$ 134$ million in 2012 to $\$ 457$ million in 2013. These findings are significant for managed care providers as they reconcile providing access to medications for members while containing costs for clients. The increases in use and costs of compounded medications may indicate a nascent trend that managed care providers should understand and plan for.

Compounded prescriptions represented a similar percentage of users' total prescription claims in both years of the study (6.9\% in 2012, 6.8\% in 2013). However, as a percentage of users' total prescription cost, compounded medications increased by $76.2 \%$ from 2012 to 2013. The National Council for Prescription Drug Programs implemented the revised standard D.0, effective January 1, 2012. ${ }^{28}$ The coverage change incorporated inclusion of all ingredients in the compound medication for reimbursement as opposed to just the most expensive ingredient. Although the new standard went into effect January 1, 2012, pharmacy benefit managers had until April 1, 2012, to adopt and implement the standard. The pharmacy benefit manager providing data for this study adopted the standard starting January 1, 2012, but some claims that were inconsistent with D.0 were accepted until April 1, 2012. Implementation of the D.0 standard beginning in the second quarter of 2012 may have, in part, contributed to lower the ingredient costs for compounded medications in 2012.

The decrease in median cost for compound users' noncompounded prescriptions was surprising. Further investigation indicated that the primary cause was an increase in the generic fill rate for noncompounded prescriptions among these patients from 2012 to 2013 (data not shown). 
Utilization and Costs of Compounded Medications for Commercially Insured Patients, 2012-2013

TABLE 4 Ten Most Expensive Ingredients in Compounded Medications by User Age and Sex, 2013

\begin{tabular}{|c|c|c|c|c|c|c|c|c|}
\hline \multirow{2}{*}{ 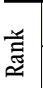 } & \multicolumn{2}{|c|}{$<10$ Years } & \multicolumn{2}{|c|}{ 10-19 Years } & \multicolumn{2}{|c|}{ 20-29 Years } & \multicolumn{2}{|c|}{ 30-39 Years } \\
\hline & $\mathrm{F}$ & M & $\mathrm{F}$ & M & $\mathrm{F}$ & M & $\mathrm{F}$ & M \\
\hline 1 & Oseltamivir & Oseltamivir & Gabapentin & Gabapentin & Gabapentin & Gabapentin & Gabapentin & Gabapentin \\
\hline 2 & Lansoprazole & Omeprazole & Fluticasone proprionate & Fluticasone proprionate & Fluticasone proprionate & Ketamine $\mathrm{HCl}$ & Ketamine $\mathrm{HCl}$ & Ketamine $\mathrm{HCl}$ \\
\hline 3 & Fluticasone proprionate & Lansoprazole & Flurbiprofen & Flurbiprofen & Ketamine $\mathrm{HCl}$ & Flurbiprofen & Fluticasone proprionate & Flurbiprofen \\
\hline 4 & Omeprazole & Methylcobalamin & Ketamine $\mathrm{HCl}$ & Ubiquinol & Flurbiprofen & Fluticasone proprionate & Flurbiprofen & Fluticasone proprionate \\
\hline 5 & Sildenafil & Leucovorin calcium & Custom Lipo-Max & Ketamine $\mathrm{HCl}$ & Custom Lipo-Max & Custom Lipo-Max & Custom Lipo-Max & Testosterone \\
\hline 6 & Tacrolimus & Sildenafil & Cyclobenzaprine $\mathrm{HCl}$ & Custom Lipo-Max & Pracasil Plus & Cyclobenzaprine $\mathrm{HCl}$ & Cyclobenzaprine $\mathrm{HCl}$ & Cyclobenzaprine $\mathrm{HCl}$ \\
\hline 7 & Nystatin & Ubiquinol & Pracasil Plus & Cyclobenzaprine $\mathrm{HCl}$ & Cyclobenzaprine $\mathrm{HCl}$ & Baclofen & Pracasil Plus & Custom Lipo-Max \\
\hline 8 & Pracasil Plus & Sodium bicarbonate & Baclofen & Oseltamivir & Baclofen & Lipoderm base & Baclofen & Baclofen \\
\hline 9 & Baclofen & Tacrolimus & Lipoderm base & Pracasil Plus & Mometasone furoate & Pracasil Plus & Lipoderm base & Lipoderm base \\
\hline 10 & Sodium bicarbonate & PCCA-Plus & Oseltamivir & Baclofen & Lipoderm base & Mometasone furoate & Bupivacaine $\mathrm{HCl}$ & Ethoxy diglycol \\
\hline \multirow{2}{*}{ 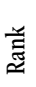 } & \multicolumn{2}{|c|}{ 40-49 Years } & \multicolumn{2}{|c|}{ 50-59 Years } & \multicolumn{2}{|c|}{ 60-69 Years } & \multicolumn{2}{|c|}{$\geq 70$ Years } \\
\hline & $\mathrm{F}$ & M & $\mathrm{F}$ & M & $\mathrm{F}$ & M & $\mathrm{F}$ & M \\
\hline 1 & Gabapentin & Gabapentin & Gabapentin & Gabapentin & Gabapentin & Gabapentin & Gabapentin & Gabapentin \\
\hline 2 & Ketamine $\mathrm{HCl}$ & Ketamine $\mathrm{HCl}$ & Ketamine $\mathrm{HCl}$ & Ketamine $\mathrm{HCl}$ & Ketamine $\mathrm{HCl}$ & Ketamine $\mathrm{HCl}$ & Ketamine $\mathrm{HCl}$ & Ketamine $\mathrm{HCl}$ \\
\hline 3 & Flurbiprofen & Flurbiprofen & Flurbiprofen & Flurbiprofen & Flurbiprofen & Flurbiprofen & Flurbiprofen & Flurbiprofen \\
\hline 4 & Fluticasone proprionate & Custom Lipo-Max & Custom Lipo-Max & Custom Lipo-Max & Custom Lipo-Max & Custom Lipo-Max & Custom Lipo-Max & Custom Lipo-Max \\
\hline 5 & Custom Lipo-Max & Cyclobenzaprine $\mathrm{HCl}$ & Cyclobenzaprine $\mathrm{HCl}$ & Cyclobenzaprine $\mathrm{HCl}$ & Cyclobenzaprine $\mathrm{HCl}$ & Cyclobenzaprine $\mathrm{HCl}$ & Cyclobenzaprine $\mathrm{HCl}$ & Cyclobenzaprine $\mathrm{HCl}$ \\
\hline 6 & Cyclobenzaprine $\mathrm{HCl}$ & Fluticasone proprionate & Fluticasone proprionate & Baclofen & Baclofen & Baclofen & Baclofen & Baclofen \\
\hline 7 & Baclofen & Baclofen & Baclofen & Testosterone & Fluticasone proprionate & Alprostadil & Lipoderm base & Lipoderm base \\
\hline 8 & Lipoderm base & Testosterone & Lipoderm base & Lipoderm base & Lipoderm base & Lipoderm base & Ketoprofen & Ketoprofen \\
\hline 9 & Pracasil Plus & Lipoderm base & Progesterone & Fluticasone proprionate & Progesterone & Testosterone & Diclofenac sodium & Testosterone \\
\hline 10 & Progesterone & Ethoxy diglycol & Diclofenac sodium & Bupivacaine $\mathrm{HCl}$ & Mometasone furoate & Fluticasone proprionate & Bupivacaine $\mathrm{HCl}$ & Diclofenac sodium \\
\hline
\end{tabular}

There appear to be no other data in the peer-reviewed literature with which to compare the results of this analysis. Prior research on compounding by community pharmacists relied on pharmacists' self-reports of their prescription-dispensing volumes. The current data, on the other hand, represent a nationwide population and all of the claims submitted by eligible members for compounded medications for the 2 years studied. There are no comparable published data on compounded prescription costs.

The prevalence of compound users was consistent across the United States, as most states exhibited rates similar to the national average. Only 4 states had a prevalence of compound users greater than $2 \%$ in 2013 . Future research focused on states with high proportions of compound users may identify factors that predict compounded medication use and that contribute to the increasing number and costs of compounded prescriptions.

Given the variety of drug therapy problems that compounding can address, diversity in the most frequently compounded drugs by age and sex was expected. Claims for patients younger than 10 years represented several therapeutic indications. However, the most frequently compounded drugs and most expensive ingredients were very similar across all adult age and sex groups. For example, 20-29-year-old women and 60-69-year-old men had 9 of the 10 most frequently compounded drugs in common. The only drugs that were different between these groups were the hormone replacement products progesterone (women) and testosterone (men). The fact that pain management and hormone replacement were well represented in the most frequently compounded drugs is not surprising, as pharmacists have previously reported these as significant niche areas for pharmacy compounding, and two thirds of compound users were women.9,13,29

Prior research indicated that pharmacists were frequently called upon by physicians to recommend specific compounded formulations appropriate to their patients' medical needs. ${ }^{29,30}$ Pharmacists may develop drug formulations based on their own research and experience, or they may obtain standardized formulations from medical and pharmacy journals, compounding suppliers, or professional colleagues. Standardization is generally beneficial, in that pharmacists who employ well-characterized formulations are more likely to compound medications of high quality, safety, and purity. ${ }^{31}$ The high degree of association of several drugs in the same prescriptions suggests that a few standardized topical pain formulations were widely adopted.

The sources of the formulations have not been rigorously investigated. However, there are several references that pharmacists may use to support their compounding practice. Every issue of the International Journal of Pharmaceutical Compounding (IJPC), for example, includes articles on professional and scientific issues related to compounding and specific example formulations for compounded medications. The formulations published in IJPC typically include quality control and 
stability information. The compounding supplier PCCA claims a "database of more than 8,000 proprietary formulations that have been pre-tested" and employs pharmacists to provide compounding-related technical support to their 3,600 member pharmacists in the United States. ${ }^{32}$ Thus it is plausible that the homogeneity in most frequently prescribed drugs was due, at least in part, to a few standardized topical pain formulations having been widely recommended by compounding pharmacists throughout the United States.

The average utilization of 2 compounded prescriptions PUPY was unexpectedly low, considering that the most frequently compounded drugs were typically recommended for medical issues with longer expected durations of therapy, such as chronic pain and hormone replacement. ${ }^{26,33-40}$ The data suggest instead that most compounded medications were used for acute conditions. If so, the cost versus benefit relationship of the compounded medications would warrant further study, as there are numerous treatment modalities for acute pain syndromes, including manufactured drug products of several pharmacologic classes. It is also possible that the compounded medications were prescribed for chronic conditions, but the users discontinued them after a short duration of use for some reason, such as unsatisfactory therapeutic response or loss of insurance coverage. These data argue for research into patient satisfaction and adherence to therapy with compounded medications to elucidate the determinants of compounded medication use.

Health plans and pharmacy benefit managers have responded to the increase in the prevalence of compound users and costs of compounded medications by excluding ingredients used in compounding from reimbursement. Express Scripts announced in June 2014 that 1,000 ingredients used in compounding would no longer qualify for reimbursement beginning July $1,2014 .^{3}$ While the full list is confidential, a subset of 25 noncovered ingredients was released to pharmacies. With the exceptions of lidocaine, testosterone, estradiol, estriol, progesterone, and triamcinolone acetonide, all of the 10 most frequently compounded drugs and 10 most expensive ingredients for adult age groups ( $\geq 20$ years old) for 2013 appear on the excluded ingredient list (disclosed with permission). It is not clear if these exceptions will continue to be reimbursed. It is impossible to predict whether patients will continue to pay out of pocket for nonreimbursed compounded medications. However, the reimbursement of compounded medications for commercially insured patients is expected to decrease in 2014 due to the effects of the extensive ingredient exclusion lists.

\section{Limitations}

There were several limitations, many of which were derived from the exclusive use of pharmacy claims data. The study population consisted only of commercially insured patients. Workers compensation claims, Medicare claims, and noninsured prescriptions were not represented in the study. The study population was members who were eligible at any time throughout the 2-year study period, so claims from chronic compound users who were not continuously eligible may have decreased the PUPY utilization value. An unknown fraction of pharmacies do not accept pharmacy benefit cards for compounded medications. ${ }^{41}$ However, insured patients who purchased compounded medications from a nonparticipating pharmacy could submit a claim for reimbursement of the prescription, and those self-submitted claims were included in the database.

The study results are generalizable to retail pharmacy claims, as they constituted more than $99 \%$ of the compounded medication claims. Claims from hospitals, mail-order pharmacies, or other nonretail pharmacies constituted less than $1 \%$ of the compounded medication claims.

Finally, the data did not include medical claims or diagnosis codes associated with conditions for which compounded medications were being prescribed. Inferences regarding the therapeutic indications for compounded medications were based on the drugs' therapeutic classifications and users' age and sex.

\section{Conclusions}

This is the first published study to profile trends in use of compounded medications using a diverse, nationwide pharmacy dataset. Compound users represented $1.4 \%$ of eligible members in 2013. The average ingredient cost for compound users' compounded prescriptions (\$710.36) was greater than for noncompounded prescriptions (\$160.20). The 1-year increase in average compounded prescription costs (130.3\%) was also greater than for noncompounded prescriptions (7.7\%). Although prevalence of compound users and the PUPY utilization of compounded prescriptions increased only slightly between 2012 and 2013, the mean and median cost of compounded medications increased dramatically during this time. Text mining revealed that drug combinations characteristic of topical pain formulations were among the most frequently compounded medications for adults.

\section{Authors}

TIMOTHY MCPHERSON, PhD, is Professor of Pharmaceutical Sciences, School of Pharmacy, Southern Illinois University, Edwardsville, Illinois, and PATRICK FONTANE, PhD, is Professor of Sociology, Department of Liberal Arts, St. Louis College of Pharmacy, St. Louis, Missouri. REETHI IYENGAR, PhD, is Senior Manager, and ROCHELLE HENDERSON, PhD, is Senior Director, Health Services Research, Express Scripts Holding Company, St. Louis, Missouri.

AUTHOR CORRESPONDENCE: Timothy McPherson, PhD, SIUE School of Pharmacy, 200 University Park Dr., Campus Box 2000, Edwardsville, IL 62026. Tel.: 618.650.5148; E-mail: tmcpher@siue.edu. 


\section{DISCLOSURES}

Southern Illinois University Edwardsville School of Pharmacy and St. Louis College of Pharmacy are members of Professional Compounding Centers of America (PCCA). No proprietary or confidential information regarding PCCA was consulted in conducting and reporting this research. No outside funding was used in this research, and the authors report no financial or other conflicts of interest.

All authors contributed equally to study concept and design. Iyengar and Henderson collected the data, and all authors participated in data interpretation. McPherson wrote the manuscript, along with Fontane, Iyengar, and Henderson, and all authors contributed equally to manuscript revision.

\section{ACKNOWLEDGMENTS}

The authors would like to acknowledge Chris Markson, PhD candidate, New Jersey Institute of Technology, for his assistance with data analysis and especially for his help in association rule mining. The authors also thank the anonymous reviewer who identified the Michigan initiative to standardize pediatric compounded medications

\section{REFERENCES}

1. Allen L. Guidelines for compounding practices. In: Allen L. The Art, Science, and Technology of Pharmaceutical Compounding. 4th ed. Washington, DC: American Pharmacists Association; 2012:1-18.

2. The United States Pharmacopeial Convention. (795) Pharmaceutical compounding—nonsterile preparations. In: United States Pharmacopeia and National Formulary, USP37-NF32. Rockville, MD: The United States Pharmacopeial Convention; 2014

3. Express Scripts. Closing the compounding loophole. 2014. Available at: http://lab.express-scripts.com/insights/drug-options/closing-the-compounding-loophole. Accessed November 20, 2015.

4. Optum. Compounding pharmacies: a costly challenge. 2014. Available at: https://www.optum.com/thought-leadership/compounding-pharmaciescostly-challenge.html. Accessed November 20, 2015

5. Pollack A. Pharmacies turn drugs into profits, pitting insurers vs. compounders. New York Times. August 14, 2014. Available at: http://nyti. ms/loyHsp7. Accessed November 20, 2015.

6. Centers for Disease Control and Prevention. Multistate outbreak of fungal infection associated with injection of methylprednisolone acetate solution from a single compounding pharmacy-United States, 2012. MMWR Morb Mortal Wkly Rep. 2012;61(41):839-42.

7. Centers for Disease Control and Prevention. Multistate outbreak of fungal meningitis and other infections. Case count. October 30, 2015. Available at: http:// www.cdc.gov/hai/outbreaks/meningitis.html. Accessed November 20, 2015.

8. Qureshi N, Wesolowicz L, Stievater T, Lin AT. Sterile compounding: clinical, legal, and regulatory implications for patient safety. J Manag Care Spec Pharm. 2014;20(12):1183-91. Available at: http://www.amcp.org/JMCP/2014/ December/18850/1033.html.

9. Glassgold JM. Compounded drugs. Congressional Research Service. June 3, 2013. Available at: http://fas.org/sgp/crs/misc/R43082.pdf. Accessed November 20, 2015.

10. International Academy of Compounding Pharmacists. What is compounding? Available at: https://iacp.site-ym.com/?page=1. Accessed November 20, 2015

11. Professional Compounding Centers of America. About compounding Available at: http://www.protectmycompounds.com/what-is-compounding/. Accessed November 20, 2015

12. Cauthon KA, Bowman BJ, Gurney MK. Compounding practices and beliefs of Arizona pharmacists. Int J Pharm Compd. 2013;17(2):154-61.
13. Huffman DC, Holmes ER. Specialty compounding for improved patient care: a national survey of compounding pharmacists. Int J Pharm Compd. 2006;10(6):462-68.

14. Huffman DC, Holmes ER. Specialty compounding for improved patient care: 2006 national survey of compounding pharmacists. Int J Pharm Compd. 2008;12(1):74-82

15. McPherson TB, Fontane PE, Jackson KD, et al. Prevalence of compounding in independent community pharmacy practice. J Am Pharm Assoc (2003). 2006;46(5):568-73

16. Academy of Managed Care Pharmacy. HHS finalizes rule for prescription drug benefit design under essential health benefits to implement Affordable Care Act provisions and clarifies preventive coverage for certain OTC items. 2013. Available at: http://amcp.org/WorkArea/DownloadAsset. aspx?id=16173.

17. National Center for Health Statistics. Health, United States, 2013: with special feature on prescription drugs. 2014. Available at: http://www.cdc. gov/nchs/data/hus/hus13.pdf. Accessed November 20, 2015

18. Brossette SE, Sprague AP, Hardin M, Waites KB, Jones WT, Moser SA Association rules and data mining in hospital infection control and public health surveillance. J Am Med Inform Assoc. 1998;5(4):373-81.

19. Demeter J, Szász B. Data mining based on medical diagnosis. Proceedings of the 7th International Conference on Applied Informatics. 2007;1:261-67. Available at: http://icai.ektf.hu/pdf/ICAI2007-voll-pp261-267.pdf. Accessed November 20, 2015

20. Ji Y, Ying H, Dews $P$, et al. A potential causal association mining algorithm for screening adverse drug reactions in postmarketing surveillance. IEEE Trans Inf Technol Biomed. 2011;15(3):428-37.

21. Ordonez C, Omiecinski E, de Braal L, et al. Mining constrained association rules to predict heart disease. Proceedings of the 2001 IEEE International Conference on Data Mining, November 29-December 2, 2001, San Jose, CA. Data Mining. 2001;433-40.

22. Payus C, Sulaiman N, Shahani M, Abu Bakar A. Association rules of data mining application for respiratory illness by air pollution database. Intern J Basic Appl Sci. 2013;13(3):11-16. Available at: http://www.ijens.org/ Vol_13_I_03/136503-7474-IJBAS-IJENS.pdf. Accessed November 20, 2015

23. Rashid MA, Hoque T, Sattar A. Association rules mining based clinical observations. Available at: http://arxiv.org/abs/1401.2571. Accessed November 20, 2015.

24. Allen L. Baclofen 5\%, gabapentin 5\%, ketoprofen 10\%, and lidocaine 5\% in pluronic lecithin organogel. Int J Pharm Compd. 2010;14(6):514.

25. Allen L. Ketoprofen 5\% and lidocaine hydrochloride 0.5\% topical gel. Int J Pharm Compd. 2010;14(6):520.

26. Asbill S, Sweitzer SM, Spigener S, Romero-Sandoval A. Compounded pain formulations: what is the evidence? Int J Pharm Compd. 2014;18(4):278-86.

27. Compounding formulas database. International Journal of Pharmaceutical Compounding. Available at: http://compoundingtoday.com/Formulation/ Formula.cfm. Accessed November 20, 2015.

28. National Government Services, Inc. Common Electronic Data Interchange companion document. Instructions related to transactions based on NCPDP Telecommunication Standard Version D.0. February 8, 2011. Available at: http://www.cms.gov/Medicare/Billing/ ElectronicBillingEDITrans/downloads/NCPDPD0CG.pdf. Accessed November 17, 2015.

29. Yancey V, Yakimo R, Perry A, McPherson TB. Perceptions of pharmaceutical care among pharmacists offering compounding services. J Am Pharm Assoc (2003). 2008;48(4):508-14

30. McPherson T, Fontane P. Patient-centered care in the community-based compounding practice setting. J Am Pharm Assoc. 2010;50(1):37-44.

31. Michigan Pediatric Safety Collaboration. State-wide initiative to standardize the compounding of oral liquids in pediatrics. Available at: http:// mipedscompounds.org. Accessed November 20, 2015. 
32. Professional Compounding Centers of America. What is PCCA? Available at: http://www.pccarx.com/patients/what-is-pcca-patients. Accessed November 20, 2015.

33. Anitescu M, Benzon HT, Argoff CE. Advances in topical analgesics. Curr Opin Anaesthesiol. 2013;26(5):555-61.

34. Ettinger B, Wang SM, Leslie RS, et al. Evolution of postmenopausal hormone therapy between 2002 and 2009. Menopause. 2012;19(6):610-15.

35. Hickey M, Elliott J, Davison SL. Hormone replacement therapy. BMJ. 2012;344:e763.

36. Panay N, Hamoda H, Arya R, et al. The 2013 British Menopause Society $\&$ Women's Health Concern recommendations on hormone replacement therapy. Menopause Int. 2013;19(2):59-68. Available at: http://min.sagepub. com/content/19/2/59.long. Accessed November 20, 2015.
37. Ruiz AD, Daniels KR. The effectiveness of sublingual and topical compounded bioidentical hormone replacement therapy in post-menopausal women: an observational cohort study. Int J Pharm Compd. 2014;18(1):70-77.

38. Schmidt P. The 2012 hormone therapy position statement of the North American Menopause Society. Menopause. 2012;19(3):257-71.

39. Smith BH, Lee J, Price C, Baranowski AP. Neuropathic pain: a pathway for care developed by the British Pain Society. Br J Anaesth. 2013;111(1):73-79.

40. Stephenson K, Neuenschwander PF, Kurdowska AK. The effects of compounded bioidentical transdermal hormone therapy on hemostatic, inflammatory, immune factors; cardiovascular biomarkers; quality-of-life measures; and health outcomes in perimenopausal and postmenopausal women. Int J Pharm Compd. 2013;17(1):74-85.

41. McElhiney LF. Optimizing third-party reimbursement for compounded medications. Int J Pharm Compd. 2013;17(3):201-04. 